\title{
Prevalence and Predictors of the Use of Sunscreen Amongst Medical Students: A Multi-center Cross- sectional Study
}

Muhammad Mustafa Memon ${ }^{1}$, Muzzammil Manzoor ${ }^{2}$, Muhammad Moinuddin Ashrafi ${ }^{3}$, Sahlish Kumar ${ }^{1}$, Zaiyn Ul Haq ${ }^{1}$, Simra Irfan ${ }^{1}$, Zunaira Navid ${ }^{1}$, Muhammad A. Khan ${ }^{1}$, Izza Shahid ${ }^{4}$, Maheen Nisar ${ }^{5}$, Shehryar Shaikh ${ }^{1}$, Samran N. Hassan ${ }^{1}$, Vanita Motiani ${ }^{4}$, Maaz S. Khan ${ }^{6}$

1. Internal Medicine, Dow University of Health Sciences, Karachi, PAK 2. Internal Medicine, Dow University of Health Science, Karachi, PAK 3. Internal Medicine, Dow Medical College, Karachi, PAK 4. Internal Medicine, Ziauddin University Hospital, Karachi, PAK 5. Biochemistry, Ziauddin University Hospital, Karachi, PAK 6. Medicine, Civil Hospital Karachi, Dow University of Health Sciences, Karachi, PAK

Corresponding author: Muzzammil Manzoor, muzzimanzoor@outlook.com

\section{Abstract \\ Objective}

Sun exposure is a primary preventable risk factor for skin cancer. Sunscreen has been shown to reduce the risk of certain skin cancers such as squamous cell carcinoma and melanoma. We aimed to assess the prevalence and predictors of sunscreen use among medical students in Karachi.

\section{Methods}

A multi-center cross-sectional study was conducted among 578 students from multiple medical universities in Karachi, Pakistan. The levels of use of sunscreen were recorded using a comprehensive questionnaire consisting of 29 questions. Descriptive statistics were used and p-values less than 0.05 calculated using the chi-square test were considered significant.

\section{Results}

A majority ( $\mathrm{n}=441,73.9 \%)$ of the participants in this study were female students. Sunscreen use was prevalent in 415 (69.5\%) participants. Female students were more aware of the risk of skin cancer from extended sun exposure $(\mathrm{n}=186,72.4 \%)$. Sunscreen use was significantly associated with gender $(\mathrm{p}<0.001)$ and the propensity to get sunburned easily $(\mathrm{p}=0.001)$. Few $(\mathrm{n}=19,5.0 \%)$ students reported being well-versed regarding skin cancer and its risk factors. Most participants were aware of the use of sunscreen for sunburn prevention ( $n=473,79.2 \%)$, though knowledge of the additional benefits of sunscreen, such as the prevention of skin cancer ( $\mathrm{n}=257,43.0 \%)$ and aging $(\mathrm{n}=199,33.3 \%)$, was lacking.

\section{Received 05/09/2019 Review began 05/21/2019 Review ended 06/03/2019 Published 06/17/2019}

(c) Copyright 2019

Memon et al. This is an open access article distributed under the terms of the Creative Commons Attribution License CC-BY 3.0., which permits unrestricted use, distribution, and reproduction in any medium, provided the original author and source are credited

\section{Conclusion}

There is an evident lack of knowledge of the importance of sunscreen protection among medical students, particularly regarding the prevention of skin cancer and skin aging. However, an overall positive attitude was observed regarding the use of sunscreen among female students. Medical students are an imperative part of our future healthcare system and should be adequately informed on sunscreen benefits and skin cancer prevention.

Categories: Dermatology, Medical Education, Environmental Health

Keywords: prevalence, predictors, sunscreen, sunblock, medical students

\section{Introduction}

Skin cancer is regarded as one of the most common types of cancer globally, with an especially high incidence rate amongst fair-skinned individuals. Although the incidence rate of skin cancer is significantly lower amongst Africans, Asians and those of Latin American, or American-Indian descent, it manifests with significant mortality due to the atypical presentations of these cases [1]. Of particular concern is the fact that there have been increasing occurrences in both melanoma and non-melanoma skin cancers worldwide. In the US alone, melanoma incidence rates have doubled from 1982 to 2011, and in the absence of

How to cite this article

Memon M, Manzoor M, Ashrafi M, et al. (June 17, 2019) Prevalence and Predictors of the Use of Sunscreen Amongst Medical Students: A Multi-center Cross-sectional Study. Cureus 11(6): e4926. DOI 10.7759/cureus.4926 
interventions, 112,000 new cases are projected till 2030 [2]. The International Agency for Research on Cancer (IARC) estimates a total of 428 new cases in 2018 alone, comprising a staggering $46.0 \%$ of the total number of cases in a five-year span [3].

The vast majority of melanomas (65.0-95.0\%) are attributable to ultraviolet radiation (UVR) exposure, in particular, UV-A and UV-B radiation [4]. UVR has damaging effects on the skin by inducing DNA mutations, immunosuppression, and oxidative stress, hence leading to skin aging, actinic keratosis and DNA damage [5-6]. It is thought that UVR mutates the p53 tumor suppressor gene, a gene responsible for DNA repair, hence causing "expansion of mutated keratinocytes and initiation of skin cancer" [7]. Sunscreen, on the other hand, primarily consists of active ingredients that act either as UVR absorbers or as agents which reflect or scatter radiation [8]. These active ingredients range from organic to mineral compounds such as $\mathrm{TiO} 2$, and can reduce the risk of squamous cell carcinoma, and melanoma [9-10].

The southern city of Karachi is regarded as a cornerstone of Pakistan’s economy, with an estimated population of over 17 million people, with a gross domestic product of approximately \$144 billion [11-12]. The prevention of cancer in the workforce of Karachi is therefore of tantamount importance to Pakistan's economy as a whole. Furthermore, being located closer to the equator, the city of Karachi receives higher UVR levels, placing its denizens at more risk [13]. Medical students are exposed to harmful UV-A and UV-B radiation during transportation and whilst walking to classes or taking part in summer activities. Use of sunscreen has also been tied to factors such as gender and nationality. A study amongst European university students from 13 different countries found that $83.0 \%$ of men and $94.0 \%$ of women were sunbathed, and that sun protection use whilst sunbathing was $63.0 \%$ in men and $87.0 \%$ in women [14]. Furthermore, there has never been a study of this scope conducted within Pakistan regarding the use of sunscreen and its predictors. Thus, our study aims to fill this gap in research by uncovering such predictors and also by evaluating the frequency of sunscreen use by medical students in day-to-day work. In a developing country like Pakistan which is already plagued by multifarious problems, the increasing incidence of melanomas is an additional burden on human and socio-economic resources. Hence, the collected data and its findings could be used to subsequently create policies to combat conditions caused by UVR, and thus alleviate some of the burden placed on the Pakistani healthcare system.

\section{Materials And Methods}

\section{Study Design and Participants}

A multi-center cross-sectional study was conducted from April to May 2018 in Karachi. Using the random sampling technique, self-administered questionnaires were distributed amongst students of multiple medical universities in Karachi and a total of 578 responses were received. The participants gave informed consent in writing, and were assured that participation in the study was voluntary and anonymity would be maintained. Only students enrolled in the Bachelors of Medicine and Bachelors of Surgery (MBBS) programs of these universities were included in this study.

\section{Questionnaire}

A literature search was done for studies related to sun awareness and sunscreen use before crafting the questionnaire. The questionnaire comprised three sections with a total of 32 questions. The first section collected information on demographics: age, gender, university, and socio-economic level. The second section included a set of questions investigating skin type using the Fitzpatrick scale [15], sun exposure and sun protection habits, knowledge regarding sun exposure, sunscreen and skin cancer and whether this knowledge had any effect on their sun protection habits. In the second section, the participants were also asked what factors would encourage them to use sunscreen as an open-ended question. The third section was designed for sunscreen users and contained questions inquiring about the reason of use, the frequency of application, the type and sun protection factor (SPF) value of the sunscreen used, and on what basis it was chosen.

\section{Statistical Analysis}

The data were entered and analyzed using SPSS version 24.0 (IBM, Armonk, NY). Basic descriptive analyses were performed for all independent variables. Differences in personal preferences and habits regarding sun exposure and sun protection were analyzed using the chi-squared test. P-values less than 0.05 were taken as significant.

\section{Results}

A total of 597 medical students participated in this study, of whom 441 (73.9\%) were female participants. 


\section{Cureus}

The mean age of participants was $20.7 \pm 1.6$ years. Of the total participants, 481 (81.1\%) came from a family background described as "quite well off." Regarding the Fitzpatrick scale for skin types, 215 (36.0\%) had type III, 210 (35.2\%) type II and 93 (15.6\%) type I. Six participants (1.0\%) had personal experience with skin cancer and 39 (6.5\%) reported a family history of the disease (Table 1). 


\section{Cureus}

Characteristics

Sex

Male

Female

Family background

Wealthy

Quite well off

Not very well off

Quite poor

Skin type*

Type I

Type II

Type III

Type IV

Type V

Type VI

Family history of skin cancer

Yes

No

Personal experience with skin cancer

Yes

No
No.

64

- no.

Percentage

42

6

57

9.5

19

39

556

6

1.0

590

98.8

TABLE 1: Demographic Data of Medical Students from Three Different Universities in Karachi, Pakistan, 2018 ( $n=597$ )

*Skin type was measured via the Fitzpatrick scale, as follows:

Type I - Skin always burns, never tans (palest, with freckles)

Type II - Skin usually burns, tans minimally

Type III - Skin sometimes burns mildly, tans uniformly

Type IV - Skin burns minimally, always tans well (moderate brown)

Type V - Skin very rarely burns, tans very easily (dark brown)

Type VI - Skin never burns (deeply pigmented dark brown to darkest brown)

There was no report of sunscreen use from 179 (30.0\%) participants. The majority ( $\mathrm{n}=228,38.2 \%$ ) used sunscreen mainly to avoid getting tanned, while the second-largest group ( $\mathrm{n}=165,27.6 \%)$ used it to avoid getting sunburned. Most participants $(\mathrm{n}=299,50.1 \%)$ avoided using sunscreen to prevent skin oiliness, while 


\section{Cureus}

212 (35.5\%) participants answered that they simply forgot to apply sunscreen, and 137 (22.9\%) participants said they did not use it as application was a hassle. A total of 360 (60.3\%) participants stated that they liked themselves most when they were not tanned. Of these participants, 123 (20.6\%) applied sunscreen immediately before sun exposure and 183 (30.7\%) only applied it during sunny months. Most of the students $(\mathrm{n}=340,57.0 \%)$ were content to apply sunscreen only once a day, while 27 (4.5\%) participants said they apply after it every few hours. Purchasing habits showed that most of the students ( $\mathrm{n}=131,21.9 \%)$ acquired a new tube of sunscreen once every year and an equal number $(n=131,21.9 \%)$ purchased it more than once a year. Overall, 415 people reported using sunscreen, giving a prevalence of $69.5 \%$ (Table 2).

Do you apply sunscreen every time you go out in daylight?

Mostly

Sometimes

Rarely

Never

Is your sunscreen application a seasonal habit?
Attitudes and Practices

No.

77

111

96

13

179

21.9

0

All year round

Rarely ever

How often do you reapply it?

No reapplication

Every hour

Every few hours

How often do you purchase a new tube of sunscreen

Once a year

Less than once a year

More than once a year

When do you apply sunscreen

Immediately before sun exposure

$30 \mathrm{~min}$ before sun exposure

$1 \mathrm{hr}$ before sun exposure

$2 \mathrm{hr}$ before sun exposure

What prompts you to use sunscreen?

Skin sensitivity/ condition

Doctor prescription

Avoid tan

Protection against skin cancer

Avoid sunburn 


\section{Cureus}

What prompts you to avoid using sunscreen?

\begin{tabular}{|c|c|c|}
\hline Getting tanned & 30 & 5.0 \\
\hline Forgetting to & 212 & 35.5 \\
\hline Applying is a hassle & 137 & 22.9 \\
\hline Skin looks greasy/oily & 299 & 50.1 \\
\hline Costly & 49 & 8.2 \\
\hline It feels hotter & 86 & 14.4 \\
\hline It is not effective & 80 & 13.4 \\
\hline \multicolumn{3}{|l|}{ ou like yourself most? } \\
\hline When I am tanned & 26 & 4.4 \\
\hline When I am not tanned & 360 & 60.3 \\
\hline I do not care about my tan & 176 & 29.5 \\
\hline My skin is naturally dark & 34 & 5.7 \\
\hline
\end{tabular}

TABLE 2: Attitude and Practices Regarding Sunscreen Application Amongst Medical Students

A total of 473 (79.2\%) participants were aware that sunscreen prevents sunburns, but only 257 (43.0\%) of them knew that it prevents skin cancer and 199 (33.3\%) knew sunscreen prevents skin aging. A total of 328 (54.9\%) participants answered that sunscreen use did not reverse signs of aging. A total of 378 (63.3\%) and 390 (65.3\%) participants reported sun exposure to cause sunburn and tanning, respectively. Participants were least aware ( $\mathrm{n}=205,34.3 \%$ ) about sun exposure's effects on aging (Table 3). 


\section{Cureus}

Knowledge

Does sunscreen prevent sunburn?

Yes

No

Do not know

Does sunscreen prevent skin cancer?

Yes

No

Do not know

Does sunscreen prevent skin aging?

Yes

199

153

No

Do not know

473

34

86

257

106

226
Percentage

79.2

5.7

14.4

17.8

Does sunscreen reverse signs of aging?

Yes

No

Do not know

What damage does sun exposure cause?

Sunburn

Tanning

Skin aging

Hyperpigmentation

Skin cancer

308

None

0.8

Significantly more females were knowledgeable regarding the effectiveness of sunscreen in preventing sunburn ( $\mathrm{p}=0.017$ ) and aging ( $\mathrm{p}<0.001)$. A significant association was also found between gender and the use of sunscreen, with females showing a much higher use of sunscreen as a protection method. Increased use of sunscreen, due to awareness of skin cancer from sun exposure, was also significantly associated with gender (Table 4). 


\section{Cureus}

\begin{tabular}{|c|c|c|c|c|c|c|}
\hline \multirow[b]{2}{*}{ Perceptions (agree with) } & \multicolumn{2}{|c|}{ Male } & \multicolumn{2}{|c|}{ Female } & \multirow[b]{2}{*}{ Total no. } & \multirow{2}{*}{ P-value } \\
\hline & No. & Percentage & No. & Percentage & & \\
\hline Sunscreen reverses aging & 19 & 0.33 & 38 & 0.67 & 57 & 0.379 \\
\hline Sunscreen prevents skin cancer & 71 & 27.6 & 186 & 72.4 & 257 & 0.549 \\
\hline Sunscreen prevent sunburn & 126 & 26.6 & 347 & 73.4 & $4 / 3$ & $0.017^{x}$ \\
\hline Sunscreen prevents aging & 47 & 23.6 & 152 & 76.4 & 199 & $0.007^{*}$ \\
\hline Use of sunscreen as sun protection method & 41 & 12.9 & 277 & 87.1 & 318 & $0.010^{*}$ \\
\hline Does your skin cancer knowledge enforce sunscreen use & 66 & 21.4 & 243 & 78.6 & 309 & $0.008^{*}$ \\
\hline
\end{tabular}

TABLE 4: Association of Gender with Sunscreen Use and Knowledge of Effectiveness

*P-values are statistically significant

Of 381 respondents, 19 (5.0\%) marked their skin cancer knowledge as "excellent," 115 (30.2\%) as "good," 161 $(42.2 \%)$ as "average," and 86 (22.5\%) as "poor." Of these, 151 (39.6\%) used sunscreen with SPF 50 or more. The majority of these participants ( $\mathrm{n}=161,42.2 \%)$ had marked their skin cancer knowledge as "average," while 30 (7.9\%) of the participants did not believe in wearing sunscreen (Table 5).

\begin{tabular}{|c|c|c|c|c|c|}
\hline \multirow{2}{*}{ SPF $^{\star *}$ Used } & \multicolumn{4}{|c|}{ Rating of Skin Cancer Knowledge } & \multirow{2}{*}{ Total No. (\%) } \\
\hline & Poor (\%) & Average (\%) & Good (\%) & Excellent (\%) & \\
\hline $0-20$ & $9(2.4)$ & $4(1.0)$ & $8(0.02)$ & $1(0.3)$ & $22(5.8)$ \\
\hline $20-50$ & $31(8.1)$ & $50(13.1)$ & $42(0.1)$ & $9(2.4)$ & $132(34.6)$ \\
\hline $50+$ & $22(5.8)$ & $78(20.5)$ & $46(12.1)$ & $5(1.3)$ & $151(39.6)$ \\
\hline A BB or CC cream ${ }^{\star \star \star *}$ & $17(4.5)$ & $17(4.5)$ & $9(2.4)$ & $3(0.8)$ & $46(12.1)$ \\
\hline It does not matter & $7(1.8)$ & $12(3.1)$ & $10(2.6)$ & $1(0.3)$ & $30(7.9)$ \\
\hline Total & $86(22.6)$ & $161(42.2)$ & $115(30.2)$ & $19(5.0)$ & $381(100)$ \\
\hline
\end{tabular}

\section{TABLE 5: Association of Subjective Skin Cancer Knowledge with SPF Use}

${ }^{*} \mathrm{X} 2=23.3, \mathrm{DF}=12, \mathrm{p}=0.025$

${ }^{*}$ SPF: sun protection factor.

${ }^{* * *} \mathrm{BB}=$ blemish balm, $\mathrm{CC}=$ color correction

Factors which were associated with the use of sunscreen included gender $(\mathrm{p}<0.001)$ and the risk of getting sunburned easily $(\mathrm{p}=0.001)$ as observed in Table 6 . Other variables tested included skin type, length of sun exposure, time spent swimming and playing sports, time spent on social media, tan preference and a family history of skin disorders. These variables did not show a significant association with sunscreen use (Table 6).

Predictors
Sunscreen Use

Always Mostly Sometimes Rarely Never Total no. 


\section{Cureus}

Gender

Male

Female

$\begin{array}{lll}5 & 7 & 28\end{array}$

$\begin{array}{ll}72-104 & 68\end{array}$

43

$72 \quad 155$

Skin type*

Type

Type II

Type III

Type IV

Type V

Type VI

Length of sun exposure

$1-5 \mathrm{hr}$

5-10 hr

$>10 \mathrm{hr}$

$\begin{array}{lll}14 & 22 & 12 \\ 28 & 41 & 33 \\ 26 & 41 & 34 \\ 6 & 6 & 14 \\ 3 & 0 & 2 \\ 0 & 1 & 1\end{array}$

12

3

34

14

88

107

439

Hours spent swimming/playing sports

$\begin{array}{lccr}<1 & 62 & 95 & 75 \\ 1-2 & 12 & 13 & 17 \\ 2-3 & 2 & 1 & 0 \\ 3-4 & 0 & 1 & 1 \\ 4-5 & 0 & 0 & 1 \\ >5 & & 1 & 1\end{array}$

Hours spent on social media

$\begin{array}{lcc}<2 & 13 & 14 \\ 2-4 & 24 & 39 \\ 4-6 & 23 & 26 \\ 6-8 & 13 & 22 \\ >10 & 4 & 10\end{array}$

Skin preference

$\begin{array}{lccccc}\text { Do not care about tan } & 18 & 24 & 24 & 46 & 64 \\ \text { Tanned } & 5 & 1 & 6 & 86 \\ \text { Not tanned } & 8 & 80 & 58 & 72 & 357 \\ \text { Skin is naturally dark } & 5 & 6 & 8 & 5\end{array}$

Ease of sunburn

$\begin{array}{lccccc}\text { A couple hours in sun } & 25 & 40 & 43 & 47 & 203 \\ \text { Extended periods in sun } & 33 & 52 & 40 & 52 & 249 \\ \text { Never gets sunburned } & 18 & 17 & 13 & 29 & 65\end{array}$




\section{Cureus}

Family history of skin disorders

$\begin{array}{lllllll}\text { Yes } & 5 & 5 & 7 & 9 & 12 & 38 \\ \text { No } & 71 & 106 & 88 & 122 & 167 & 554\end{array}$

\section{TABLE 6: Factors Associated with Sunscreen Use Amongst Medical Students in Karachi, Pakistan}

*Skin type was measured via the Fitzpatrick scale, as follows:

Type I - Skin always burns, never tans (palest, with freckles)

Type II - Skin usually burns, tans minimally

Type III - Skin sometimes burns mildly, tans uniformly

Type IV - Skin burns minimally, always tans well (moderate brown)

Type V - Skin very rarely burns, tans very easily (dark brown)

Type VI - Skin never burns (deeply pigmented dark brown to darkest brown)

\section{Discussion}

This cross-sectional study comprising 597 medical students sought to assess the knowledge, attitudes and practices of these students regarding sunscreen. We found varying levels of knowledge of the protective effects of sunscreen, with an overall intermediate to poor understanding among students. Less than half of the students were aware of the ability of sunscreen to prevent skin cancer and aging [16-18], while only $9.5 \%$ of participants knew that sunscreen can reverse the signs of aging [19]. Furthermore, female students were significantly more aware of the protection offered by sunscreen against sunburn and skin aging, and were compelled to utilize sunscreen due to their knowledge more than their male colleagues. This is in concert with previously published studies [20-22]. A possible explanation for this could be the more image-conscious and appearance-focused nature of women compared with men [23].

Moreover, around three-fifths of the students in our study liked themselves most when they were not tanned, which is in concordance with another Asian study [24]. Consequently, avoidance of tanning and sunburn were cited as the major reasons for sunscreen use by our cohort. This is in contrast to the study conducted by Awadh et al. [25], in which medical students cited friends and media as the main influencers of sunscreen use. Surprisingly, half of the students in our sample avoided sunscreen as they claimed it made their skin looks "greasy/oily."

The prevalence of sunscreen use was $69.5 \%$ in our population, which was slightly higher than the $61.0 \%$ and 59.0\% prevalence reported by Jerkegren et al. [26] and Alberg et al. [27], respectively. The hot and humid climate of Karachi might play a part in this elevated prevalence of sunscreen use. Furthermore, data were collected during the summer months of April to May which could also contribute to the increased sunscreen use observed in our study. About half of students who reported sunscreen use applied it at least 30 minutes before sun exposure, which is recommended for adequate binding to the skin [28-29].

Given the lack of awareness regarding the protective effects of sunscreen against skin cancer and aging, medical students should be educated with the help of awareness campaigns and initiatives. Medical students represent a vital asset to society as future health care providers; hence, equipping them with adequate knowledge on sunscreen benefits would ultimately lead to increased sunscreen use among both patients and the general population.

\section{Limitations}

Our study has some limitations. Convenience sampling was used, which may introduce selection bias. Sunscreen use was self-reported by the participants and could not be verified. Questionnaires were filled during the summer months of April to May which may not reflect sunscreen use attitudes and practices throughout the year. The frequency of sunscreen use per day was not recorded and should be explored in 
future studies.

\section{Conclusions}

Sunscreen use was prevalent among a significant majority of medical students. However, knowledge regarding the protective effects of sunscreen, particularly against skin cancer and aging, was observed to be deficient in our cohort. The strongest predictors of sunscreen use were observed to be prevention of tanning and sunburn. Further measures to educate medical students in regard to the benefits of sunscreen should be undertaken to ultimately increase its use.

\section{Additional Information \\ Disclosures}

Human subjects: Consent was obtained by all participants in this study. Animal subjects: All authors have confirmed that this study did not involve animal subjects or tissue. Conflicts of interest: In compliance with the ICMJE uniform disclosure form, all authors declare the following: Payment/services info: All authors have declared that no financial support was received from any organization for the submitted work. Financial relationships: All authors have declared that they have no financial relationships at present or within the previous three years with any organizations that might have an interest in the submitted work. Other relationships: All authors have declared that there are no other relationships or activities that could appear to have influenced the submitted work.

\section{References}

1. Byrd-Miles K, Toombs EL, Peck GL: Skin cancer in individuals of African, Asian, Latin-American, and American-Indian descent: differences in incidence, clinical presentation, and survival compared to Caucasians. J Drugs Dermatol. 2007, 6:10-16.

2. Guy GP, Thomas CC, Thompson T, et al.: Vital signs: melanoma incidence and mortality trends and projections - United States, 1982-2030. MMWR Morb Mortal Wkly Rep. 2015, 64:591-596.

3. GLOBOCAN 2018: population fact sheets - Pakistan . (2018). Accessed: April 30, 2019: http://gco.iarc.fr/today/data/factsheets/populations/586-pakistan-fact-sheets.pdf.

4. Armstrong BK: How sun exposure causes skin cancer: an epidemiological perspective . Cancer Prevention Cancer Causes. Springer Netherlands, 2004. 89-116. 10.1007/978-94-017-0511-0_6

5. Hoeijmakers JHJ: DNA damage, aging, and cancer. N Engl J Med. 2009, 361:1475-1485. 10.1056/NEJMra0804615

6. Armstrong BK, Kricker A: The epidemiology of UV induced skin cancer . J Photochem Photobiol B. 2001, 63:8-18. 10.1016/s1011-1344(01)00198-1

7. Benjamin CL, Ananthaswamy HN: p53 and the pathogenesis of skin cancer. Toxicol Appl Pharmacol. 2007, 224:241-248. 10.1016/j.taap.2006.12.006

8. Murphy GM: Sunblocks: mechanisms of action. Photodermatol Photoimmunol Photomed. 1999, 15:34-36. 10.1111/j.1600-0781.1999.tb00051.x

9. Green A, Williams G, Neale R, et al.: Daily sunscreen application and betacarotene supplementation in prevention of basal-cell and squamous-cell carcinomas of the skin: a randomised controlled trial. Lancet. 1999, 354:723-729. 10.1016/S0140-6736(98)12168-2

10. Green AC, Williams GM, Logan V, et al.: Reduced melanoma after regular sunscreen use: randomized trial follow-up. J Clin Oncol. 2011, 29:257-263. 10.1200/JCO.2010.28.7078

11. World urbanization prospects: The 2018 revision, online edition. United Nations, Department of Economic and Social Affairs. (2018). Accessed: April 30, 2019: https://population.un.org/wup/.

12. Which are the largest city economies in the world and how might this change by 2025 ? -

PricewaterhouseCoopers UK economic outlook, November 2009. (2009). Accessed: April 30, 2019:

https://web.archive.org/web/20130531000745/http://www.ukmediacentre.pwc.com/imagelibrary/downloadMedi MediaDeta....

13. Ultraviolet radiation: how it affects life on earth . (2001). Accessed: April 30, 2019: https://earthobservatory.nasa.gov/features/UVB/uvb_radiation3.php.

14. Peacey V, Steptoe A, Sanderman R, Wardle J: Ten-year changes in sun protection behaviors and beliefs of young adults in 13 European countries. Prev Med. 2006, 43:460-465. 10.1016/j.ypmed.2006.07.010

15. Goldman M: Universal classification of skin type. Simplified Facial Rejuvenation. Shiffman M, Mirrafati S, Lam S, Cueteaux C (ed): Springer, Berlin, Heidelberg; 2008. 47-50. 10.1007/978-3-540-71097-4_3

16. Naylor MF, Farmer KC: The case for sunscreens. A review of their use in preventing actinic damage and neoplasia. Arch Dermatol. 1997, 133:1146-1154. 10.1001/archderm.1997.03890450096012

17. Ananthaswamy HN, Loughlin SM, Cox P, Evans RL, Ullrich SE, Kripke ML: Sunlight and skin cancer: inhibition of p53 mutations in UV-irradiated mouse skin by sunscreens. Nat Med. 1997, 3:510-514. 10.1038/nm0597-510

18. Hughes MC, Williams GM, Baker P, Green AC: Sunscreen and prevention of skin aging: a randomized trial . Ann Intern Med. 2013, 158:781-790. 10.7326/0003-4819-158-11-201306040-00002 


\section{Cureus}

19. Randhawa M, Wang S, Leyden JJ, Cula GO, Pagnoni A, Southall MD: Daily use of a facial broad spectrum sunscreen over one-year significantly improves clinical evaluation of photoaging. Dermatol Surg. 2016, 42:1354-1361. 10.1097/DSS.0000000000000879

20. Al Robaee AA: Awareness to sun exposure and use of sunscreen by the general population . Bosn J Basic Med Sci. 2010, 10:314-318. 10.17305/bjbms.2010.2678

21. Zhou M, Zhuang W, Yuan Y, Li Z, Cai Y: Investigation on vitamin D knowledge, attitude and practice of university students in Nanjing, China. Public Health Nutr. 2016, 19:78-82. 10.1017/S1368980015000373

22. Rasmussen S, O'Connor RC: Factors influencing anticipated decisions about sunscreen use. J Health Psychol. 2005, 10:585-595. 10.1177/1359105305053441

23. Rozin P, Fallon A: Body image, attitudes to weight, and misperceptions of figure preferences of the opposite sex: a comparison of men and women in two generations. J Abnorm Psychol. 1988, 97:342-345. 10.1037/0021-843X.97.3.342

24. Gao Q, Liu G, Liu Y: Knowledge, attitude and practice regarding solar ultraviolet exposure among medical university students in Northeast China. J Photochem Photobiol B. 2014, 140:14-19.

10.1016/j.jphotobiol.2014.07.002

25. Awadh AI, Jamshed S, Elkalmi RM, Hadi H: The use of sunscreen products among final year medicine and pharmacy students: a cross-sectional study of knowledge, attitude, practice, and perception. J Res Pharm Pract. 2016, 5:193-199. 10.4103/2279-042X.185731

26. Jerkegren E, Sandrieser L, Brandberg Y, Rosdahl I: Sun-related behaviour and melanoma awareness among Swedish university students. Eur J Cancer Prev. 1999, 8:27-34. 10.1097/00008469-199902000-00004

27. Alberg AJ, Herbst RM, Genkinger JM, Duszynski KR: Knowledge, attitudes, and behaviors toward skin cancer in Maryland youths. J Adolesc Health. 2002, 31:372-377. 10.1016/S1054-139X(02)00377-4

28. Sunscreens explained. Accessed: April 30, 2019: https:/www.skincancer.org/prevention/sunprotection/sunscreen/sunscreens-explained.

29. Jerant AF, Johnson JT, Sheridan CD, Caffrey TJ: Early detection and treatment of skin cancer. Am Fam Physician. 2000, 62:357-368. 